УДК 616.895.87:178.8-021.58:616.8.07:616-089.17

Для цитирования: Бохан Н.А., Селиванов Г.Ю., Мандель А.И., Лаврова У.А., Блонский К.А., Сальников А.А. Клиническая типология абстинентного синдрома при зависимости от синтетических каннабиноидов (спайсов) у больных параноидной шизофренией. Сибирский вестник психиатрии и наркологии. 2019; 1 (102): 62-70. https://doi.org/10.26617/1810-3111-2019-1(102)-62-70

\title{
Клиническая типология абстинентного синдрома при зависимости от синтетических каннабиноидов (спайсов) у больных параноидной шизофренией
}

Бохан Н. А. ${ }^{1,2}$, Селиванов Г.Ю., ${ }^{1,3,5,6,7}$, Мандель А.И.', Лаврова У.А. ${ }^{3}$, Блонский К.А. ${ }^{4}$, Сальников А.А. ${ }^{8}$

${ }^{1}$ НИИ психического здоровья, Томский национальный исследовательский медицинский центр

Российской академии наук

Россия, 634014, Томск, ул. Алеутская, 4

${ }^{2}$ Сибирский государственный медицинский университет

Россия, 634050, Томск, Московский тракт, 2

${ }^{3}$ Сибирский федеральный научно-клинический центр федерального медико-биологического агентства

Россия, 636035, Северск, ул. Мира, д. 4

${ }^{4}$ Нижневартовская психоневрологическая больница

Россия, 628615, Нижневартовск, ул. Интернациональная, д. 39 «»

${ }^{5}$ Религиозная организация - духовная образовательная организация высшего образования

«Томская духовная семинария Томской епархии Русской Православной Церкви»

Россия, 634009, Томск, ул. пр. Ленина, д. 82

${ }^{6}$ Томская клиническая психиатрическая больнииа

Россия, 634014, Томск, ул. Алеутская, д. 4

${ }^{7}$ Станциия скорой медицинской помощчи

Россия, 634059, г. Томск, ул. Говорова, д. 25.

${ }^{8}$ Ноябрьский психоневрологический диспансер

Россия, 629810, Ноябрьск, ул. Мира, д. 37 «б»

\section{PEЗЮME}

Несвоевременное выявление и лечение абстинентного синдрома, вызванного синтетическими каннабиноидами (спайсами) у больных параноидной шизофренией, нарушает их реабилитационный потенциал, приводит к регоспитализациям и, как следствие, укорачивает ремиссии, снижает статистическую информативность этого вида наркозависимости. Цель - изучить клинику абстинентного синдрома у лиц, страдающих параноидной шизофренией и зависимых от синтетических каннабиноидов (спайсов). Методы исследования: клинико-психопатологический, катамнестический, статистический. Результаты. Дифференцирована симптоматика эндогенного процесса и симптоматика абстинентного синдрома, вызванного употреблением синтетических каннабиноидов. Описаны варианты реализации острых состояний, катализируемых спайсами. Ведущей особенностью при коморбидном течении абстинентного синдрома, вызванного употреблением синтетических каннабиноидов, и эндогенного процесса на фоне антипсихотической терапии является тотальная редукция симптоматики. При употреблении спайсов у больных параноидной шизофренией формируется абстинентный синдром, протекающий в три этапа и по шести вариантам: депрессивно-астеническому, дисфорическому без расстройств сна, дисфорическому с нарушениями сна, паранойяльному (тревожно-фобическому), галлюцинаторно-параноидному (делириозоподобному), полиморфному (смешанному). Варианты абстиненции отличаются друг от друга аффектом, двигательной активностью, волевыми и эмоциональными нарушениями, преобладанием расстройств мышления и фабулы бредовой интерпретации. Соматические симптомы абстиненции схожи с симптомами, вызванными несинтетическими каннабиноидами. Заключение. Синдром отмены, вызванный спайсами, формируется быстрее, чем при употреблении несинтетических каннабиноидов, и протекает дольше. При этом сглаживается негативная симптоматика параноидной шизофрении - эмоциональное обеднение и волевое снижение, меняется иерархия расстройств мышления. При купировании состояний, вызванных обострением параноидной шизофрении и употреблением синтетических каннабиноидов, наиболее вероятно развитие двух вариантов абстиненции: дисфорического без расстройств сна и галлюцинаторнопараноидного. Наибольшей эффективностью в лечении абстиненции при зависимости от синтетических каннабиноидов у больных параноидной шизофренией обладают седативные нейролептики в комбинации с транквилизаторами. 


\section{ВВЕДЕНИЕ}

Первые упоминания об употреблении синтетических каннабиноидов (СК) приходятся на начало 2000-х годов. Согласно докладу управления ООН по наркотикам за 2018 г., число людей, употребляющих несинтетические и СК, продолжает расти: за период 2006-2016 гг. их число выросло на $\approx 16 \%$, что соответствует приросту мирового населения за тот же период. В 2016 г. они стали наиболее распространенными наркотиками, чем другие. В 2017 г. как минимум однажды СК употребляли 192 млн человек в мире. В 2016 г. большое количество СК были изъяты Соединенными Штатами (5 тонн), Российской Федерацией (0,7 тонны) и Турцией (0,6 тонны). За декабрь 2017 г. СК составляли $32 \%$ от общей доли новых психоактивных веществ (ПАВ) [1, 2, 3, 4].

В течение последнего десятилетия наблюдается деформация как типичной клинической картины наркотизации $[5,6,7]$, так и синдрома отмены, вызванного СК, а также сочетание состояний, вызванных употреблением СК с параноидной шизофренией (ПШ), лидирующей по числу коморбидности при зависимости от СК $[8,9,10,11,12,13,14,15]$. Атипичность клинической картины абстиненции от СК вызвана трудностью дифференцировки и выделения нозологических категорий в связи с образованием так называемых химер [16], совмещающих в себе «извращённую» симптоматику того и другого заболевания [6].

Ранее нами и другими исследователями сообщалось, что СК вызывают краткосрочные интоксикационные психозы (длительностью менее 10-15 минут), что, в свою очередь, влечет за собой череду установления неверных диагнозов сотрудниками скорой медицинской помощи, что в прогрессии приводит к выпадению лиц с зависимостью из поля зрения наркологов, а также к искажению данных. Следует отметить и другую проблему - у больных ПШ, зависимых от СК, интоксикационные психозы часто напоминают обострение эндогенного процесса, что также искажает данные о истинном состоянии наркологической ситуации. Типологии клиники синдрома отмены, вызванного СК, уделяется меньше внимания. Соответственно и сведения о лицах, употребляющих СК и страдающих ПШ, частично утрачивают свою статистическую значимость для медицинских информационных систем.
Анализ литературных данных дает основание говорить о том, что синдром отмены при употреблении СК формируется достаточно быстро, спустя 3 недели постоянного употребления [7, 12, 13], но в современной специализированной литературе нам не встречались сведения о клинической типологии абстинентного синдрома при сочетании его с параноидной шизофренией.

\section{ЦЕЛЬ ИССЛЕДОВАНИЯ}

Изучить клиническое течение абстинентного синдрома у лиц, страдающих параноидной шизофренией и зависимых от синтетических каннабиноидов (спайсов).

МАТЕРИАЛЫ И МЕТОДЫ ИССЛЕДОВАНИЯ

Исследование выполнено на базе ФГБУ СибФНКЦ ФМБА России (Северск), ОГБУЗ «Томская клиническая психиатрическая больница» (Томск), ОГАУЗ «Станция скорой медицинской помощи» (Томск), ГБУЗ ЯмалоНенецкого автономного округа «Ноябрьский психоневрологический диспансер» (Ноябрьск), БУ ХМАО-Югры «Нижневартовская психоневрологическая больница» (Нижневартовск) за период с середины 2013 по 2018 г.

Обследовано 120 мужчин с ПШ, зависимых от СК, в среднем возрасте $30,3 \pm 0,52$ года. По семейному положению преобладали холостые $(79,16 \%$ - 95), далее следовали состоящие в браке $(12,5 \%$ - 15) и разведенные $(8,34 \%$ $10)$. В зависимости от уровня образования превалировали лица со средним образованием $(50,83 \%$ - 61), с меньшей частотой встречаемости выявлены лица со средним специальным $(30,83 \%$ - 37), неоконченным высшим $(13,33 \%$ - 16) и высшим $(5,01 \%$ - 6) образованием. $65 \%$ пациентов (78) имели II нерабочую группу инвалидности, 20\% (24) - II рабочую группу, 15\% (18) - III рабочую группу.

В дебюте психическое состояние пациентов определялось синдромом КандинскогоКлерамбо с преобладанием зрительных делириозоподобных галлюцинаций угрожающего характера, вероятно катализируемых интоксикацией, вызванной приемом СК. Течение заболевания носило непрерывно-прогредиентный характер, ремиссии были краткосрочными (1-2 месяца). Наркотизация до 7 дней провоцировала нетипичную психопродукцию с наличием зрительных галлюцинаций. Для купирования психотической симптоматики использовались типичные нейролептики. 
При длительной терапии применялись комбинации атипичных и пролонгированных нейролептиков. В ремиссии наблюдалась невыраженная негативная симптоматика, психопродукция редуцировалась, в виде следового шлейфа отмечались четко очерченные расстройства мышления по типу резонерства, символизмов, парадоксальности суждений, соскальзываний.

Критерии включения в исследование: 1) согласие пациента на участие в исследовании; 2) возраст 18-50 лет; 3) согласие пациента выполнять необходимые обследования; 4) наличие параноидной формы шизофрении с коморбидной зависимостью от синтетических каннабиноидов; 5) давность заболевания 5 и более лет.

Критерии исключения из исследования: 1) расстройства рубрик F0, F3-F9; 2) клинически значимое когнитивное снижение.

Исследование проводилось на основе клинико-психопатологического метода (оценка симптомов, синдромов и состояния больных на различных этапах течения абстинентного синдрома). Методами систематизации данных были организация в базу и обработка с помощью программы «R» для Windows с использованием описательной статистики, корреляционного анализа (Spearman Rank Order). Оценка нормальности распределения результатов проводилась с использованием критерия Колмогорова-Смирнова. Достоверность различий между выборками оценивалась с помощью t-критерия Стьюдента при уровне статистической значимости $\mathrm{p}<0,05$. Данные представлены в виде среднего арифметического (М) и ошибки среднего арифметического (m).

\section{РЕЗУЛЬТАТЫ И ОБСУЖДЕНИЕ}

В результате исследования все пациенты были разделены на 6 диагностических категорий с уточнением соответствующей диагностической группы (F12), сочетанной с параноидной шизофренией непрерывного типа течения (F20.00x): 1) острая интоксикация, вызванная употреблением СК, неосложненная (F12.00) 16 чел., 2) острая интоксикация, вызванная употреблением СК, с делирием (F12.03) - 25 чел., 3 ) психотическое состояние преимущественно бредовое, вызванное употреблением CK (F12.51) - 20 чел., 4) психотическое состояние преимущественно галлюцинаторное, вызванное употреблением СК (F12.52) - 23 чел.; 5) абстинентное состояние неосложненное, вызванное употреблением СК, депрессивноастенический вариант (F12.30) - 19 чел., 6) аб- стинентное состояние с делирием, вызванное употреблением CK (F12.4x) - 17 чел.

У каждого из обследуемых проявлялись симптомы абстиненции до купирования психотического состояния и после, ввиду чего мы выделили 6 вариантов, а также 3 этапа, описание которых приведено далее. Ведущую роль при дифференцировании состояний, приведших к госпитализации - постпсихотического абстинентного синдрома, вызванного СК, от эндогенного процесса сыграла фактически тотальная редукция симптоматики (на фоне антипсихотической терапии) и нестабильность психопродуктивных образований.

Выявлено, что первый этап абстиненции, вызванной СК, возникает в течение 2-3 часов после последнего употребления, при котором наблюдаются мидриаз, «необычный» блеск глаз, «стеклянность, опустошённость взгляда», субиктеричность склер, бледность кожи, заострённость черт лица, потливость до гипергидроза, перемежающееся чувство жара и холода, головная боль, потемнение в глазах, тахикардия, повышение артериального давления (140180 мм рт.ст., при возможном резком снижении до 90-60 мм рт.ст), изредка боли в мышцах, тошнота. Введение антипсихотиков на первом этапе приводило к более легкому течению абстиненции. Далее состояние развивалось по одному из представленных ниже вариантов.

Депрессивно-астенический вариант абстиненции (наблюдался у 51,6\% пациентов) характеризовался субъективным ощущением мышечной слабости, замедленностью движений и речи, формальным, односложным типом ответов. Явления гипобулии всецело оказывали влияние на двигательные способности пациентов. Внимание их было фиксировано на внутренних переживаниях. Настроение понижалось от гипотимического до депрессивного. В мышлении, помимо типичных формальных расстройств мышления, присущих эндогенным больным, превалировали брадифрения, тугоподвижность, обстоятельность, соскальзывания, разноплановость. Мотивация была сужена на поиске тимолептика или суициде, что отмечалось и другими авторами [13]. На втором и третьем этапах к расстройствам мышления присоединялись другие с тенденцией к доминированию - паранойяльная настроенность, символичность, паралогии и амбивалентность. В последующем выявлялась тимолептическая мотивация поиска наркотика с компульсивным влечением. 
Дисфорический вариант абстиненции (выявлен у 16,8\% пациентов) характеризовался легкой двигательной и речевой заторможенностью, спонтанно переходящей в моторное возбуждение с непредсказуемой оборонительной агрессией. Доминировал гневливо-злобный аффект. Внимание было рассеянным и отвлекаемым, мышление - ускоренным по темпу, наблюдались паранойяльная настроенность и разноплановость. Мотивом поведения была месть, защита. На втором и третьем этапах преобладали неструктурированные идеи отношения, ущерба, компульсивное желание мести.

Дисфорический вариант абстиненции
с нарушением сна диагностирован у $25,2 \%$ пациентов. Он отличался от предыдущего мотивацией употребления СК со снотворной целью. Можно было прогнозировать реализацию агрессии, растущую в зависимости от длительности бессонницы.

Паранойяльный (тревожно-фобический) вариант абстиненции диагностирован у 20,4\% пациентов и характеризовался психомоторным возбуждением - выраженной двигательной (неусидчивость, обеспокоенность) и речевой (торопливость, сбивчивость, невнятность, вплоть до бессвязности) активностью. Действия больных катализировались неструктурированными нетипичными для больных шизофренией идеями преследования, отношениями, имеющими свойство быстрой медикаментозной редукции и критики. Фабула имела стереотипное содержание - «страх наказания, задержки сотрудниками силовых структур». Действия больных несли дефензивную мотивацию. Они искали защищенное надежное убежище, оберегались «баррикадами». Симптомы гипобулии отсутствовали. Внимание пациентов было отвлекаемым, рассеянным. В мышлении доминировали тахифрения, соскальзывания, перемежающиеся со шперрунгами ментизмы, разноплановость, паранойяльная настроенность, типичные и для обострения эндогенного заболевания.

Галлюцинаторно-параноидный (абстинентный синдром с делирием) вариант абстиненции имел место у 21,6\% пациентов. Характеризовался выраженным психомоторным возбуждением - двигательной (неусидчивость, обеспокоенность) и речевой активностью по типу монолога, переходящей в «словесную окрошку». Действия их катализировались вербальными и зрительными галлюцинациями угрожающего, комментирующего и оскорбляющего характеров, которые развивали структурированные идеи преследования, отношения, воздействия, не укладывающиеся в типичную фабулу бреда больных шизофренией, а также имеющие свойство быстрой медикаментозной редукции с формированием стойкой критики (в отличие от типичного бреда больных шизофренией). Фабула имела традиционно-типичное содержание - «страх наказания, задержки сотрудниками спецслужб, внедрение жучков, слежка». Изредка наблюдались переходы в стойкие бредовые конструкции. Действия больных носили оборонительный характер - они защищались, искали обидчиков, были аллоагрессивны. Внимание было отвлекаемым, рассеянным. В мышлении доминировали тахифрения, соскальзывания, перемежающиеся со шперрунгами ментизмы, разноплановость, паранойяльная настроенность, паралогии, которые были присущи так же и эндогенному процессу.

Полиморфный (смешанный) вариант абстиненции наблюдался у $8,4 \%$ больных. В отличие от вышеописанных, он был не структурирован. На втором этапе больные ощущали «жар всего тела, перемежающийся с ознобом», брадипноэ, диспноэ. Через 5-6 часов (без терапии) наблюдались рост продуктивной симптоматики, а также общий гипергидроз, легкий гипертонус мышц, гиперрефлексия, фасцикулярные подергивания (изредка), лавирование артериального давления и частоты сердечных сокращений, редко мелко-размашистый тремор и ринорея. Без терапии наблюдалась диссомния (исключение: дисфорическая с нарушением сна, галлюцинаторно-параноидная абстиненция).

На третьем этапе (2-е сутки) имели место сенестопатии («мурашки по телу, стекание воды, щекотание, жжение, холод, пульсация, вялость, вздутие, сухость»), постепенно нарастала аффективная насыщенность. Влечение к СК больные отрицали, но при выписке употребляли СК без борьбы мотивов, используя психологические защиты - замещение, проекция, компенсация, регрессия, вытеснение [12]. При повторном употреблении СК у больных субъективно наблюдалось временное облегчение симптомов абстиненции, что являлось одним из факторов рецидива. Явления абстиненции окончательно редуцировались лишь к концу 23-й недели на фоне терапии (пик симптомов приходился на 1-ю неделю). Больные становились скрытными, замкнутыми, наблюдался рост негативной симптоматики, но без апатоабулии, в отличие от типичных больных с параноидной шизофренией [4]. 
При купировании абстиненции (депрессивно-астенической), вызванной СК, а также психотического галлюцинаторного состояния, инициированного СК, наиболее вероятен переход в абстиненцию дисфорическую без расстройств сна, что подтверждает положительная корреляция слабой силы $(\mathrm{r}=0,20)$. При купировании психотического бредового состояния, вызванного СК, наиболее возможен переход в абстиненцию галлюцинаторно-параноидную, что подтверждает положительная корреляция умеренной силы $(\mathrm{r}=0,33)$. В то время как при купировании абстиненции с делирием, вызванной СК, наиболее вероятным является переход в абстиненцию галлюцинаторно-параноидную, что подтверждает положительная корреляция умеренной силы $(\mathrm{r}=0,29)$.

В качестве купирующей терапии состояний, приведших к госпитализации, применялся инфузионный метод с седативными нейролептиками (галоперидол 10 мг/сут или дроперидол 25 мг/сут) и транквилизаторами (феназепам 4 мг/сут), витаминами группы «В». Редукция галлюцинаций, вызванных СК, происходила в течение 1-2 недель. Бредоподобные идеи, вызванные СК, нивелировались к концу 1-го месяца лечения. Для формирования первичной критики и с целью редукции психопродуктивной и негативной симптоматики использовались комбинации атипичных нейролептиков (азалептин, рисполепт) и нейролептиков пролонгированного действия (клопиксол-депо, галоперидол-деканоат, сенорм, модитен-депо).

При формировании ремиссии у больных наблюдалась невыраженная негативная симптоматика в виде эмоционального обеднения и гипобулии, психопродуктивная симптоматика в виде сопровождающего шлейфа - не очерченных расстройств мышления по типу резонерства, символизмов, паралогий, соскальзываний.

\section{ЗАКЛЮЧЕНИЕ}

При употреблении спайсов у больных параноидной шизофренией формируется абстинентный синдром, протекающий в три этапа и по шести вариантам: депрессивно-астеническому, дисфорическому без расстройств сна, дисфорическому с преимущественными нарушениями сна, паранойяльному (тревожно-фобическому), галлюцинаторно-параноидному (делириозоподобному), полиморфному (смешанному). Варианты абстиненции отличаются друг от друга аффектом, двигательной активностью, волевыми и эмоциональными нарушениями, преобладанием расстройств мышления и фабулы бреда. Сo- матические симптомы абстиненции имеют сходство с симптомами, вызванными несинтетическими каннабиноидами. Синдром отмены, вызванный спайсами, формируется быстрее, чем при употреблении несинтетических каннабиноидов, и протекает продолжительнее по времени. При этом сглаживается негативная симптоматика параноидной шизофрении - эмоциональное обеднение, волевое снижение, меняется иерархия расстройств мышления. При купировании состояний, вызванных обострением параноидной шизофрении, а также употреблением синтетических каннабиноидов, наиболее вероятно развитие двух вариантов состояний абстиненции: дисфорического без расстройств сна и галлюцинаторно-параноидного. Наибольшей эффективностью в лечении абстиненции при зависимости от синтетических каннабиноидов у больных параноидной шизофренией обладают седативные нейролептики в комбинации с транквилизаторами.

\section{КОНФЛИКТ ИНТЕРЕСОВ}

Авторы заявляют об отсутствии возможных конфликтов интересов в связи с публикацией данной статьи.

\section{ИСТОЧНИК ФИНАНСИРОВАНИЯ}

Работа выполнена в рамках основной темы НИР НИИ психического здоровья Томского НИМЦ «Распространенность, клиникопатобиологические закономерности формирования и патоморфоза психических и поведенческих расстройств, вызванных употреблением психоактивных веществ в социально-организованных популяциях (профилактический, реабилитационный аспекты) и темы основного плана НИР на 2019-2021 гг. «Комплексное исследование клинико-психопатологических закономерностей и патобиологических механизмов формирования и прогредиентности социально значимых психических и поведенческих расстройств с разработкой инновационных методов ранней диагностики, персонализированных стратегий терапии и профилактики». Номера госрегистрации АAАA15-115123110064-5 и AAAA-A19119020690013-2 соответственно.

\section{СООТВЕТСТВИЕ ПРИНЦИПАМ ЭТИКИ}

Работа соответствует этическим стандартам Хельсинской декларации ВМА (Протокол заседания этического комитета НИИ психического здоровья № 114 от 22 октября 2018 г.).

\section{ЛИТЕРАТУРА}

1. Всемирный доклад о наркотиках. 2018 [Электронный ресурс] // URL.: https://www.unodc.org/ doc/wdr2018/WDR_2018_PressRealeaseRUS.PDF (дата обращения 12.01.2019) 
2. Головко А.И., Баринов В.А., Иванов М.Б., Головко Е.С. Систематизация синтетических каннабиноидов и их биотрансформация. Наркология. 2016; 9 (175): 66-78.

3. Головко А.И., Иванов М.Б., Бонитенко Е.Ю., Баринов В.А., Башарин В.А. Краткий обзор синтетических каннабиноидов, появившихся в незаконном обороте в 2014-2015 гг. Наркология. 2016; 2 (168): 59-73.

4. Mechoulam R., Feigenbaum J.J., Lander N., Segal M., Jorbe T.U., Hiltunen A.J., Consroe P. Enantiomeric cannabinoids: stereospecificity of psychotropic activity. Experientia. 1988; 44 (9): 762-764.

5. Бохан Н.А., Семке В.Я. Коморбидность в наркологии. Томск : Изд-во Том. ун-та, 2009: 510.

6. Langas A.M., Malt U.F., Opjordsmoen S. In-depth study of personality disorders in first-admission patients with substance use disorders. BMC Psychiatry. 2012; 12:180. https://doi:10.1186/1471-244X$12-180$

7. Бохан Н.А., Селиванов Г.Ю. Клиническая типология психопатологических расстройств у потребителей синтетических каннабиноидов (спайсов). Сибирский вестник психиатрии и наркологии. 2015; 4 (89): 18-23.

8. Николкина Ю.А., Замогильный С.И. Систематическое употребление синтетических каннабиноидов у лиц молодого возраста: особенности клинических проявлений и предрасполагающие факторы. Вопросы наркологии. 2017; 6: 96-98.

9. Гуреева Д.А., Гуреев Д.А., Уварова И.А., Лекомцев В.Т. Дифференциальная диагностика шизофрении, органических психозов и интоксикационных психозов вследствие употребления синтетических каннабиноидов. Вопросы наркологии. 2016; 11-12: 113-118.

10. Патрикеева О.Н., Кормилина О.М., Овчинников А.А., Соловьева И.Г., Теркулов Р.А., Иксанова Д.Д. Обзор организации реабилитационных мероприятий для пациентов с синдромом зависи- мости от синтетических каннабиноидов в условиях стационарного отделения. Наркология. 2016; 7 (173): 15-19.

11. Синевич А.А., Копытов А.В., Зезина А.Ю. Клинико-психологические особенности зависимости от синтетических каннабиноидов. Bonpocbl наркологии. 2017; 6: 108-110.

12. Бохан Н.А., Селиванов Г.Ю., Блонский К.А., Лаврова У.А. Особенности социально-психологической адаптации пациентов с параноидной формой шизофрении, страдающих зависимостью от синтетических каннабиноидов (спайсов). Сибирский вестник психиатрии и наркологии. 2018; 2 (99): 93-98. https://doi.org/10.26617/18103111-2018-2(99)-93-98

13. Винникова М.А., Шахова С.М. Клинические проявления и общие подходы к терапии при синдроме зависимости от синтетических каннабиноидов («Спайс»). Наркология. 2016; 4 (172): 34-43.

14. Бохан Н.А., Селиванов Г.Ю., Блонский К.А. Характеристика абстинентного синдрома у лиц, страдающих зависимостью от употребления синтетических каннабиноидов (спайсов). Cuбирский вестник психиатрии и наркологии. 2016; 4 (93): 45-50.

15. Черепкова Е.В., Гуревич К.Г., Счастный Е.Д., Антонов А.Р. Общая характеристика наркотиков-аналогов и их составляющих: курительные смеси «спайс», энтеогены. Системный анализ $и$ управление в биомедицинских системах. 2012; 11 (3): 685-688.

16. Langas A.M., Malt U.F., Opjordsmoen S: Substance use disorders and comorbid mental disorders in first-time admitted patients from a catchment area. Eur Addict Res. 2012, 18:16-25.

Поступила в редакцию 01.11.2018 Утверждена к печати 18.02.2019

Бохан Николай Александрович, академик РАН, д.м.н., профессор, заслуженный деятель науки РФ, руководитель отделения аддиктивных состояний, директор НИИ психического здоровья, заведующий кафедрой психиатрии, наркологии и психотерапии ФГБОУ ВО СибГМУ Минздрава России.

Селиванов Георгий Юрьевич, преподаватель психологии кафедры церковно-практических дисциплин Томской духовной семинарии; врач-психиатр, врач-психиатр-нарколог, врач-психотерапевт, психолог общепсихиатрического, медико-реабилитационного отделений и психоневрологического диспансера ФГБУ СибФНКЦ ФМБА России, СКБ; приемного отделения ОГБУЗ «Томской клинической психиатрической больницы»; специализированной выездной психиатрической бригады областного государственного автономного учреждения здравоохранения «Станции скорой медицинской помощи».

Мандель Анна Исаевна, д.м.н., профессор, ведущий научный сотрудник отделения аддиктивных состояний НИИ психического здоровья.

Лаврова Ульяна Анатольевна, клинический психолог общепсихиатрического отделения ФГБУ СибФНКЦ ФМБА России, СКБ.

Блонский Кирилл Андреевич, врач-психиатр, врач-психиатр-нарколог поликлинического отделения Нижневартовской психоневрологической больницы.

Сальников Алексей Александрович, врач-психиатр, врач-психиатр-нарколог, врач-психотерапевт психиатрического отделения, психиатрического отделения дневного пребывания, отделения медицинской реабилитации для лиц с наркологическим расстройством ГБУЗ Ямало-Ненецкого автономного округа «Ноябрьский психоневрологический диспансер». 
УДК 616.895.87:178.8-021.58:616.8.07:616-089.17

For citation: Bokhan N.A., Selivanov G.Yu., Mandel A.I., Lavrova U.A. Blonsky K.A., Salnikov A.A. Clinical typology of withdrawal syndrome in dependence on synthetic cannabinoids (spice) in patients with paranoid schizophrenia. Siberian Herald of Psychiatry and Addiction Psychiatry. 2019; 1 (102): 62-70. https://doi.org/10.26617/18103111-2019-1(102)-62-70

\title{
Clinical typology of withdrawal syndrome in dependence on synthetic cannabinoids (spice) in patients with paranoid schizophrenia
}

\section{Bokhan N. A. ${ }^{1,2}$, Selivanov G.Yu. ${ }^{1,3,5,6,7}$, Mandel A.I. ${ }^{1}$, Lavrova U.A. $^{3}$, Blonsky K.A. ${ }^{4}$, Salnikov A.A. ${ }^{8}$}

\author{
${ }^{1}$ Mental Health Research Institute, Tomsk National Research Medical Center, Russian Academy of Sciences \\ Aleutskaya Street 4, 634014, Tomsk, Russian Federation \\ ${ }^{2}$ Siberian State Medical University \\ Moskovsky Trakt 2, 634050, Tomsk, Russian Federation \\ ${ }^{3}$ Siberian Federal Scientific Clinical Center of Federal Medicobiological Agency \\ Mira Street 4, 636035, Seversk, Russian Federation \\ ${ }^{4}$ Nizhnevartovsk Psychoneurological Hospital \\ Internationalnaya Street, 39 “B”, 628615, Nizhnevartovsk, Russian Federation \\ ${ }^{5}$ Religious Organization - Spiritual Educational Organization of Higher Education \\ "Tomsk Theological Seminary of the Tomsk Diocese of the Russian Orthodox Church" \\ Lenin Avenue Street 82, 634009, Tomsk, Russian Federation. \\ ${ }^{6}$ Regional State Budgetary Healthcare Institution "Tomsk Clinical Psychiatric Hospital” \\ Aleutskaya Street 4, 634014, Tomsk, Russian Federation \\ ${ }^{7}$ Regional State Autonomous Healthcare Institution "Emergency Medical Care Station" \\ Govorova Street 25, 634059, Tomsk, Russian Federation \\ ${ }^{8}$ State Budgetary Institution of Health of the Yamal-Nenets Autonomous Okrug \\ "Noyabrsk Psychoneurological Dispensary" \\ Mira Street, 37 “b”, 629810, Noyabrsk, Russian Federation
}

\section{ABSTRACT}

Introduction. Late detection, differentiation and treatment of withdrawal symptoms caused by synthetic cannabinoids (spice) in patients with paranoid schizophrenia interfere with their rehabilitation potential, lead to rehospitalization, as a result shorten remission, and reduce the statistical information content of this kind of drug dependence. The aim is to study the clinical picture of withdrawal syndrome in persons with paranoid schizophrenia who are dependent on synthetic cannabinoids (Spice). Methods: collection of anamnesis, follow-up history, clinical, psychopathological, statistical. Results. Symptoms of the endogenous process and symptoms of the withdrawal syndrome due to use of synthetic cannabinoids were differentiated. Variants of actualization of acute states catalyzed by Spice were described. The leading role in the separation of abstinence caused by the synthetic cannabinoids and the endogenous process was rendered by the ability of the states caused by Spice to virtually totally reduce the symptoms, against the background of the antipsychotic therapy, the instability of the psycho-production. Conclusion. When the use of Spice in patients with paranoid schizophrenia is formed, withdrawal flowing in three phases and six variants: depressive, asthenic, dysphoric without sleep disorders, dysphoric with sleep disorders, paranoiac (anxious-phobic), hallucinatory-paranoid (delirium-form), polymorphic (mixed). Abstinence variants differ from each other by affect, movement activity, and influence of volitional and emotional disturbances, predominance of thought disorders and plot of delusional interpretation. Somatic withdrawal symptoms were similar to those caused by non-synthetic cannabinoids. The withdrawal syndrome caused by Spice was formed faster than by non-synthetic cannabinoids and lasted longer, reduced negative symptoms of paranoid schizophrenia, such as emotional impoverishment and volitional reduction, changed the hierarchy of mental disorders. With the relief of acute states leading to hospitalization caused by exacerbation of paranoid schizophrenia, as well as the use of synthetic cannabinoids, the most likely occurrence of withdrawal state variants were dysphoric without sleep disorders, hallucinatory-paranoid ones. Sedative neuroleptics in combination with tranquilizers had the highest efficacy in the treatment of withdrawal due to use of synthetic cannabinoids, reduction of withdrawal symptoms occurred much faster than signs of endogenous process remission. 


\section{Keywords: synthetic cannabinoids, Spice, abstinence, dependence, schizophrenia, comorbidity.}

\section{REFERENCES}

1. World Drug Report. 2018 [Electronic resource]// URL.: https://www.unodc.org/doc/wdr2018/WDR_ 2018_Press_ReleaseENG.PDF (date of access 12.01.2019) (in Russian).

2. Golovko A.I., Barinov V.A., Ivanov M.B., Golovko E.S. Sistematizatsiya sinteticheskikh kannabinoidov i ikh biotransformatsiya [Systematization of synthetic cannabinoids and their biotransformation]. Narkologiya - Narcology. 2016; 9 (175): 66-78 (in Russian).

3. Golovko A.I., Barinov V.A., Ivanov M.B., Golovko EGolovko A.I., Ivanov M.B., Bonitenko E.Yu., Barinov V.A., Basharin V.A. Kratkii obzor sinteticheskikh kannabinoidov? poyavivshikhsya $\mathrm{V}$ nezakonnom oborote v 2014-2015 gg. [A brief review of synthetic cannabinoids that appeared in illicit trafficking in 2014-2015]. Narkologiya - Narcology. 2016; 2 (168): 59-73 (in Russian).

4. Mechoulam R., Feigenbaum J.J., Lander N., Segal M., Jorbe T.U., Hiltunen A.J., Consroe P. Enantiomeric cannabinoids: stereospecificity of psychotropic activity. Experientia. 1988; 44 (9): 762-764.

5. Bokhan N.A., Semke V.Ya. Komorbidnost' v narkologii.[ Comorbidity in narcology]. Tomsk: Publishing house Tom. University, 2009: 510 (in Russian).

6. Langas A.M., Malt U.F., Opjordsmoen S. In-depth study of personality disorders in first-admission patients with substance use disorders. BMC Psychiatry. 2012; 12:180. https://doi:10.1186/1471-244X12-180

7. Bokhan N.A., Selivanov G.Yu. Klinicheskaya tipologiya psikhopatologicheskikh rasstroistv u potrebitelei sinteticheskikh kannabinoidov (spaisov) [Clinical typology of psychopathological disorders among users of synthetic cannabinoids (spice)]. Sibirskii vestnik psikhiatrii $i$ narkologii - Siberian Herald of Psychiatry and Addiction Psychiatry. 2015; 4 (89): 18-23 (in Russian).

8. Nikolkina Yu.A., Zamogil'nyi S.I. Sistematicheskoe upotreblenie sinteticheskikh kannabinoidov u lits molodogo vozrasta: osobennosti klinicheskikh proyavlenii i predraspolagayushchie factory [Systematic use of synthetic cannabinoids in young people: features of clinical manifestations and predisposing factors]. Voprosy narkologii - Journal of Addiction Problems. 2017; 6: 96-98 (in Russian).

9. Gureeva D.A., Gureev D.A., Uvarova I.A., Lekomtsev V.T. Differentsial'naya diagnostika shizofrenii, organicheskikh psikhozov i intoksikatsionnykh psikhozov vsledstvie upotrebleniya sinteticheskikh kannabinoidov [Differential diagnosis of schizophrenia, organic psychoses and intoxication psychoses due to the use of synthetic cannabinoids]. Voprosy narkologii - Journal of Addiction Problems 2016; 11-12: 113-118 (in Russian).

10. Patrikeeva O.N., Kormilina O.M., Ovchinnikov A.A., Solov'eva I.G., Terkulov R.A., Iksanova D.D.
Obzor organizatsii reabilitatsionnykh meropriyatii dlya patsientov s sindromom zavisimosti ot sinteticheskikh kannabinoidov $\mathrm{v}$ usloviyakh statsionarnogo otdeleniya [Review of the organization of rehabilitation activities for patients with the syndrome of dependence on synthetic cannabinoids in the inpatient unit setting]. Narkologiya - Narcology. 2016; 7 (173): 15-19 (in Russian).

11. Sinevich A.A., Kopytov A.V., Zezina A.Yu. Kliniko-psikhologicheskie osobennosti zavisimosti ot sinteticheskikh kannabinoidov [Clinical and psychological characteristics of dependence on synthetic cannabinoids]. Voprosy narkologii - Journal of Addiction Problems. 2017; 6: 108-110 (in Russian).

12. Bokhan N.A., Selivanov G.Yu., Blonskii K.A., Lavrova U.A. Osobennosti sotsial'nopsikhologicheskoi adaptatsii patsientov s paranoidnoi formoi shizofrenii, stradayushchikh zavisimost'yu ot sinteticheskikh kannabinoidov (spaisov) [Features of the socio-psychological adaptation of patients with paranoid schizophrenia suffering from dependence on synthetic cannabinoids (spice)]. Sibirskii vestnik psikhiatrii $i$ narkologii - Siberian Herald of Psychiatry and Addiction Psychiatry. 2018; 2 (99): 93-98 (in Russian). https://doi.org/10.26617/1810-3111-2018-2(99)-93-98

13. Vinnikova M.A., Shakhova S.M. Klinicheskie proyavleniya i obshchie podkhody k terapii pri sindrome zavisimosti ot sinteticheskikh kannabinoidov ("Spais") [Clinical manifestations and general approaches to therapy in the syndrome of dependence on synthetic cannabinoids ("Spice")]. Narkologiya - Narcology. 2016; 4 (172): 34-43 (in Russian).

14. Bokhan N.A., Selivanov G.Yu., Blonskii K.A. Kharakteristika abstinentnogo sindroma u lits, stradayushchikh zavisimost'yu ot upotrebleniya sinteticheskikh kannabinoidov (spaisov) [Characteristics of abstinence syndrome in people suffering from dependence on the use of synthetic cannabinoids (spice)]. Sibirskii vestnik psikhiatrii $i$ narkologii - Siberian Herald of Psychiatry and Addiction Psychiatry. 2016; 4 (93): 45-50 (in Russian).

15. Cherepkova E. V., Gurevich K. G., Schastnyj E. D., Antonov A. R. Obshchaya harakteristika narkotikov-analogov i ih sostavlyayushchih: kuritel'nye smesi "spajs", ehnteogeny [General characteristics of drugs-analogues and their components: Smoking mixtures "spice", enteogens]. Sistemnyj analiz i upravlenie v biomedicinskih sistemah - System Analysis and Control in Biomedical Systems. 2012; 11 (3): 685-688 (in Russian).

16. Langas A.M., Malt U.F., Opjordsmoen S: Substance use disorders and comorbid mental disorders in first-time admitted patients from a catchment area. Eur Addict Res. 2012, 18:16-25.

Received November 1.2018

Accepted February 18.2019 
Bokhan Nikolay A., academician of RAS, MD, Prof., Honored Scientist of the Russian Federation, Head of Addictive States Department, director of Mental Health Research Institute, Tomsk National Research Medical Center, Russian Academy of Sciences; Head of the Department of Psychiatry, Addiction Psychiatry and Psychotherapy, Siberian State Medical University, Tomsk, Russian Federation.

Selivanov Georgy Yu., lecturer of psychology of the Department of Ecclesiastical-Practical Disciplines of Tomsk Theological Seminary; psychiatrist, addiction specialist, psychotherapist, psychologist of general psychiatric, medico-rehabilitative units and psychoneurological clinic of Siberian Federal Scientific Clinical Center of Federal Medico-Biological Agency, Seversk Clinical Hospital and admitting office of Tomsk Clinical Psychiatric Hospital, specialized field psychiatric brigade of the regional state autonomous health care institution "Emergency medical care stations" Seversk, Tomsk, Russian Federation.

Mandel Anna I., MD, Professor, lead researcher of Addictive States Department, Mental Health Research Institute, Tomsk National Research Medical Center, Russian Academy of Sciences, Tomsk, Russian Federation.

Lavrova Uliyana A., clinical psychologist of the General Psychiatric Unit, Siberian Federal Scientific Clinical Center of Federal Medico-Biological Agency, Seversk Clinical Hospital, Seversk, Russian Federation.

Blonsky Kirill A., psychiatrist and addiction specialist of Polyclinic Unit, Nizhnevartovsk Psychoneurological Hospital, Nizhnevartovsk, Russian Federation.

Alexey Salnikov A., psychiatrist, psychiatrist, psychiatrist, psychotherapist of the Psychiatric Department, Psychiatric Ward of Day Care, Medical Rehabilitation Department for Patients with Substance Abuse, State Budgetary Institution of Health of the Yamal-Nenets Autonomous Okrug "Noyabrsk Psychoneurological Clinic", Noyabrsk, Russian Federation.

Selivanov Georgy Yu., gergy89selivanov@gmail.com 